\title{
Correction to: Development of Halofluorochromic Polymer Nanoassemblies for the Potential Detection of Liver Metastatic Colorectal Cancer Tumors Using Experimental and Computational Approaches
}

Derek Reichel' • Louis T. Curtis ${ }^{2}$ • Elizabeth Ehlman ${ }^{2}$ • B. Mark Evers ${ }^{3,4}$ - Piotr Rychahou ${ }^{3,4}$.

Hermann B. Frieboes ${ }^{2,5,6} \cdot$ Younsoo Bae $^{1}$

Published online: 16 July 2021

(C) Springer Science+Business Media, LLC, part of Springer Nature 2021

Correction to: Pharmaceutical Research volume 34, pages2385-2402 (2017).

https://doi.org/ 10.1007/sI 1095-017-2245-9

In this article the author name Evers, B. Mark was incorrectly written as Mark Evers B.

The original article has been corrected.

Publisher's Note Springer Nature remains neutral with regard to jurisdictional claims in published maps and institutional affiliations.

The original online version of this article was revised because the author name Evers, B. Mark was incorrectly written as Mark Evers B.

The online version of the original article can be found at https://doi.org/l 0 . | 007/s | | 095-0 17-2245-9

\footnotetext{
Younsoo Bae

younsoo.bae@uky.edu

Department of Pharmaceutical Sciences, College of Pharmacy University of Kentucky 789 South Limestone, Lexington, KY 40536, USA

2 Department of Bioengineering, School of Engineering University of Louisville 230 I South Third, Louisville, KY 40292, USA

3 Markey Cancer Center University of Kentucky 800 Rose, Lexington, KY 40536, USA

4 Department of Surgery, College of Medicine University of Kentucky 741 South Limestone, Lexington, KY 40536, USA

5 Department of Pharmacology and Toxicology, School of Medicine University of Louisville 505 South Hancock, Louisville, KY 40292, USA

6 James Graham Brown Cancer Center University of Louisville 529 South Jackson, Louisville, KY 40292, USA
} 